\title{
Modeling and Analysis of the Kinetic Influence of Liquid Sloshing Characteristics on High-Clearance Sprayers
}

\author{
Weijun Wang $\mathbb{D}$, Jing'an Feng $\mathbb{D}$, Wenkang Wan, Peng Zhang, and Songlin Yang \\ College of Mechanical and Electrical Engineering, Shihezi University, Shihezi 832000, Xinjiang, China \\ Correspondence should be addressed to Weijun Wang; wangweijun_91@163.com and Jing'an Feng; fja_mac@shzu.edu.cn
}

Received 22 March 2021; Revised 23 August 2021; Accepted 22 September 2021; Published 12 November 2021

Academic Editor: Daniel Sevcovic

Copyright (c 2021 Weijun Wang et al. This is an open access article distributed under the Creative Commons Attribution License, which permits unrestricted use, distribution, and reproduction in any medium, provided the original work is properly cited.

\begin{abstract}
To research the influence of liquid sloshing on the driving stability of high-clearance sprayers, this paper builds an equivalent liquid sloshing mechanical model and obtains the stochastic acceleration excitation of the rectangular spray tank using the Adams kinetic model, thus obtaining the relationship between the impact force, moment, and the stochastic acceleration using Fluent numerical simulation analysis. This paper makes further calculations with MATLAB/Simulink system models, and the result from comparing these two calculations shows that the equivalent strategy proposed in this paper has a better consistency. Based on the consideration of the acting forces of the additional moment due to lateral movement of the center of mass of the liquid and the dynamic pressure due to liquid sloshing in the tank, this paper builds a mathematical model of the sprayer and researches the influence of the filling ratio and vehicle velocity on the vehicle stability through stochastic acceleration excitation. The results show that, in the case of different speeds, the liquid sloshing has a small influence on the overall roll angle; in the case of different filling ratios, the liquid sloshing has a big influence on the overall roll angle, the slip angle of the center of mass, and the yaw angular velocity; the filling ratio $k=0.85$ and the speed $u=1 \mathrm{~m} / \mathrm{s}^{-2} \mathrm{~m} / \mathrm{s}$ are safe operation parameters of the sprayer. This research provides reference solutions for the stability control and optimization problems of the high-clearance sprayer and semitrailer.
\end{abstract}

\section{Introduction}

During the pesticide application process, multiple factors affect the stability of high-clearance sprayers. High-clearance sprayers are likely to roll over due to instability during the pesticide application process, which could in turn trigger casualties and economic losses; therefore, researching and analyzing the stability of working high-clearance sprayers is increasingly important. High-clearance sprayers transport a large amount of liquid, while in motion, the large-amplitude sloshing of liquid will change the load distribution on the axle of the highclearance sprayer and produce additional force and moment, thus reducing the stability of the high-clearance sprayer. Liquid sloshing is an important factor that causes instability in highclearance sprayers and is of great significance to the analysis and resolution of the working stability problems of the highclearance sprayer by building an equivalent mechanical model of the liquid sloshing of the high-clearance sprayer and researching the liquid sloshing behaviors [1-5].

Since the 1950s, the problem of liquid sloshing of mobile containers has received more attention [6]. Liquid sloshing is a common problem in engineering, and extensive researches into the transportation problems of tank trucks and the application of such symmetrical structures in engineering have been conducted [7-10]. However, the liquid sloshing in truck tanks is not a symmetrical problem, and the coupling of the liquid sloshing and the tank truck body makes such problems more complicated.

In recent years, domestic and overseas scholars have conducted numerous researches on liquid sloshing in truck tanks. Feng Ran from Jilin University built an equivalent model of liquid sloshing in truck tanks to solve associated parameters of the equivalent model by utilizing MATLAB ident system identification [11]. Pan and Ma have built an 
equivalent pendulum model of liquid sloshing using a rectangular open-moon pool as an example. Liu Chunyuan et al. took a rectangular full-open moon pool as an example, established a liquid sloshing equivalent simple pendulum model, used Lagrangian equations to establish the kinematics and dynamics equations of the simple pendulum, and then used Ibrahim to solve the moon pool based on linear potential flow theory. Kinematics, dynamics, and related mechanics equations through simultaneous equations solve the relevant parameter values of the equivalent model [12]. $\mathrm{Hu}$ Xiaoming et al. built an equivalent mechanical model of liquid forced sloshing and solved associated parameters by taking the liquid tank semitrailer as an example. Afterward, they built a semitrailer kinetic model, added the forces and moments obtained from the equivalent model to the semitrailer kinetic model, and analyzed the influence of liquid sloshing on the stability of the semitrailer [13].

To sum up, many domestic and overseas scholars have conducted multiple research on the liquid sloshing characteristics; however, they only take into account the acting force of the lateral movement of the center of mass of liquid in the tank. In practical traffic and transport, the dynamic pressure generated from the lateral sloshing of the liquid cannot be ignored. Therefore, it is necessary to conduct further research on the lateral sloshing of the liquid in the high-clearance sprayer. This paper establishes a coupling relationship between the liquid sloshing and the highclearance sprayer by building an equivalent mechanical model of the pendulum mass damping to make a synthetic analysis of the influence of liquid sloshing on the driving stability of the sprayer through simulation. The research in this paper will provide references for the modeling of the chassis system kinetic model and the stability control strategies of the high-clearance sprayer.

\section{Designing the Simulation Model}

2.1.3D High-Clearance Sprayer Model. An overall 3D model is built for the high-clearance sprayer using SolidWorks, as shown in Figure 1. The machine is mainly composed of high-clearance chassis, steering mechanism, driver cab, spray tank, spray lance, and so on, and the main parameters are shown in Table 1.

Figure 2 is the simulation flowchart of reliability verification of the liquid sloshing equivalent mechanical model in this paper. The equivalent mechanical model of liquid forced sloshing is built based on the equivalence principle, the stochastic acceleration excitation suffered by the spray tank is output based on the Adams virtual prototype simulation model, and the model of liquid forced sloshing of the spray tank is built using Fluent to conduct numerical simulation of liquid sloshing and obtain the relationship between the impact force and impact moment and the stochastic acceleration; relevant parameters of the equivalent mechanical model are obtained through the mechanical analysis of liquid sloshing in the rectangular-section spray tank to build the MATLAB/Simulink system simulation model, then the reliability of the system with the filling ratio of 0.5 is verified through Fluent, and later the coupling with the constructed kinetic model of the high-clearance sprayer is conducted to analyze the influence control factors of liquid sloshing on the stability of the high-clearance sprayer.

2.2. Adams Kinetic Model. To obtain the stochastic acceleration excitation suffered by the spray tank and dynamically to load it into the Fluent environment in real time, this paper builds a multibody kinetic simulation model of a high-clearance sprayer, converts the 3D high-clearance sprayer model equipped in the SolidWorks software into a Parasolid.xt format, and imports it into the Adams software. Besides, the model adds a rotating set to the four tires of the high-clearance sprayer separately and adds a rotating drive to the rear rotating sets separately to make the high-clearance sprayer move in a forward direction, and each component is set with parameters like material attributes, and so on [14]. The operating speed is $1 \mathrm{~m} / \mathrm{s}$, and the stochastic acceleration suffered by the spray tank in three directions is dynamically loaded into the Fluent model of liquid forced sloshing of the spray tank for the numerical simulation of the sloshing of liquid in the spray tank.

2.2.1. Tire Model. The tire is an important component of the high-clearance sprayer and is an important contact part between the high-clearance sprayer and the pavement. It bears the weight of the sprayer and the external acting force applied by the pavement to the sprayer, playing a role in force conduction between the sprayer and ground.

The Adams software has multiple tire models, with different tire models that apply to diverse working environments. According to the characteristics and requirements of a working high-clearance in the field, this paper selects the Fiala tire model, and its parameters are shown in Table 2.

2.2.2. Pavement Model. The paper mainly researches the liquid sloshing caused by uneven field pavement and does not take into account the influence of the pavement gradient on liquid sloshing; the paper establishes the requirements that meet Adams simulation pavement excitation and finally generates a Grade $E$ three-dimensional pavement surface spectrum file of $40 \mathrm{~m}$ long and $20 \mathrm{~m}$ wide in MATLAB software according to the three-dimensional pavement node generation algorithm and based on the pavement unevenness expression and pavement unevenness classification standard established according to the harmony superposition principle, and the pavement file is shown in Figure 3.

\subsection{Fluent Numerical Simulation. Two states occur during} the pesticide application process of the high-clearance sprayer, namely, the gas phase and liquid phase in the spray tank at all times, as shown in Figure 4. During the impact process, the total volume of the gas phase and liquid phase remains constant, and only the shape and position change.

Therefore, the liquid impact on the spray tank is a multiphase flow problem and can be analyzed through simulation by utilizing the VOF model. Fluent can be used for single-phase, multiphase, and complicated problems in the numerical model, for example, multiphase flow problem, 


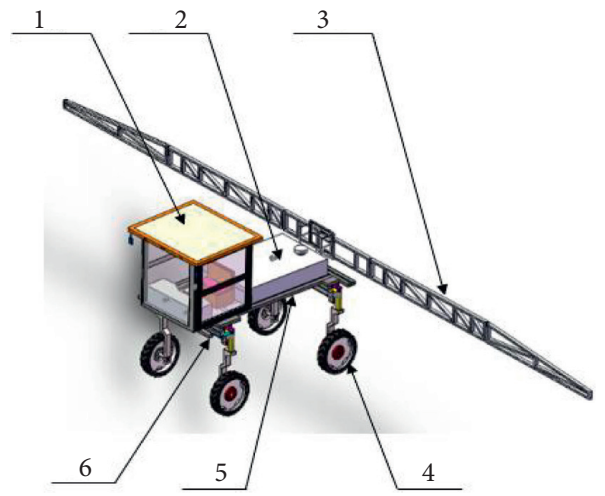

Figure 1: Overall 3D model.

TABLE 1: Main parameters of Adams overall simulation.

\begin{tabular}{lccc}
\hline Parameter & Value & Parameter & Value \\
\hline Wheelbase & $3.0 \mathrm{~m}$ & Distance between the sprung mass center and roll center & $0.3 \mathrm{~m}$ \\
Wheel track & $2.0 \mathrm{~m}$ & Rotational inertia of sprung mass surrounding roll center & $308.4 \mathrm{~kg} \mathrm{~m}^{2}$ \\
Ground clearance & $1.5 \mathrm{~m}$ & Equivalent roll stiffness of suspension & $4000.0 \mathrm{~N} \bullet \mathrm{s} \bullet \mathrm{rad}^{-1}$ \\
Total mass & $1000 \mathrm{~kg}$ & Equivalent roll damping coefficient of suspension & $20.0 \mathrm{~N} \bullet \mathrm{s} \bullet \mathrm{rad}^{-1}$ \\
Sprung mass & $976 \mathrm{~kg}$ & & \\
\hline
\end{tabular}

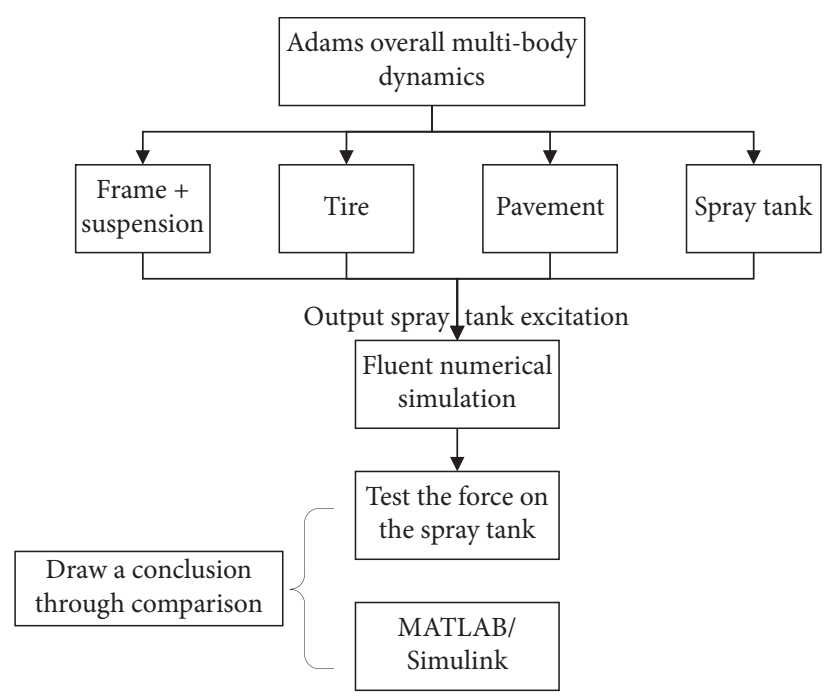

FIGURE 2: Simulation flowchart.

laminar flow problem, and turbulence problem. Table 3 shows the setting of the key parameters.

During the numerical simulation, Fluent detects the impact force of liquid sloshing to the wall surface of the spray tank and the moment of liquid sloshing to the bottom center of the spray tank.

2.4. Analysis of Simulation Results. The paper prepares the Grade $E$ stochastic pavement model required by the sprayer operating conditions through MATLAB software, then generates the stochastic pavement features suitable for Adams software simulation, and obtains the stochastic acceleration excitation output of the spray tank with Adams software simulation as the input of the Fluent software of liquid sloshing and applies $\mathrm{C}$ language to compile and expand the program codes of Fluent, which are then dynamically loaded to Fluent environment to establish the forced sloshing model of liquid in the spray tank of a highclearance sprayer, when the filling ratio in numerical simulation is $k=0.5$; the simulation results of the additional force and moment generated by liquid sloshing to the sidewall of the spray tank are shown in Figures 5 and 6.

As can be seen from Figures 5 and 6, under the influence of the external stochastic acceleration, the additional force and moment generated by liquid sloshing in the spray tank gradually become larger, then tend to be stable, and finally increase, where the maximum impact force and moment suffered by the spray tank wall surface are $19.6 \mathrm{~N}$ and $0.6 \mathrm{~N} \bullet \mathrm{m}$, respectively, and the average impact force and moment are $0.47 \mathrm{~N}$ and $0.04 \mathrm{~N} \bullet \mathrm{m}$, respectively. 
TABLE 2: Tire model parameters.

\begin{tabular}{lccc}
\hline Parameter & Value & Parameter & Value \\
\hline Tire mass & $20 \mathrm{~kg}$ & Wheel hub width & $0.17 \mathrm{~m}$ \\
Free radius of the tire & $0.38 \mathrm{~m}$ & Vertical stiffness of the tire & $190000 \mathrm{~N} \bullet \mathrm{m}^{-1}$ \\
Tire width & $0.21 \mathrm{~m}$ & Vertical damping coefficient of the tire & $50 \mathrm{~N} \bullet \mathrm{s} \bullet \mathrm{m}^{-1}$ \\
Flatness ratio of the tire & 0.55 & Static friction coefficient of the tire & 0.8 \\
Radius of the wheel hub & $0.2 \mathrm{~m}$ & Dynamic friction coefficient of the tire & 1.1 \\
\hline
\end{tabular}

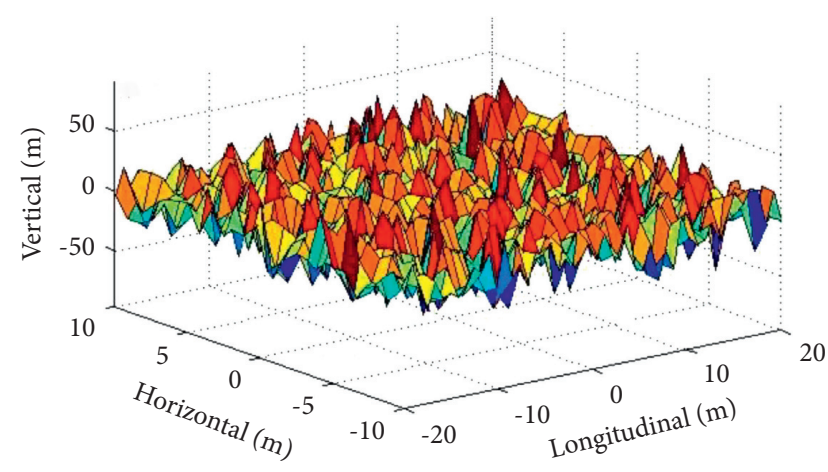

Figure 3: Grade e pavement.

To research the relationship between the stochastic acceleration excitation and the impact force and moment suffered by the wall surface of the spray tank, we apply a stochastic acceleration to the fluid region, taking the stochastic acceleration suffered by the spray tank in the $Z$ direction as an example, detect the impact force and moment suffered by the wall surface of the spray tank, and obtain the relationship between the stochastic acceleration and the impact force and moment suffered by the wall surface in the $Z$ direction, as shown in Figures 7 and 8 .

As can be seen from Figures 7 and 8, the variation trend of the stochastic acceleration applied to the spray tank in the $Z$ direction mirrors that of the impact force and moment suffered by the wall surface in the $Z$ direction, where the impact force and moment have hysteresis phenomena, which are consistent with real-life phenomena. The results show that the impact force and moment suffered by the wall surface of the spray tank are affected by the stochastic acceleration; namely, when the acceleration increases gradually, the impact force and moment suffered by the wall surface will also increase, and the variation trend is the same, where the average absolute value of the acceleration is $0.06 \mathrm{~m} / \mathrm{s}^{2}$ and the maximum value is $1.5 \mathrm{~m} / \mathrm{s}^{2}$.

\section{Building a Parallel Liquid Sloshing Mechanical Model}

To facilitate the research, liquid sloshing problems in engineering have always been designed to parallel mechanical models. This paper designs a spray tank filling system that mirrors the pendulum-mass-damping system as shown in Figure 6 and adopts the rigid system kinetics to research the response of such system under the action of external excitations.
The building of the equivalent mechanical model of the spray tank has to meet the following 4 conditions:

(1) The equivalent model must have the same mass as the liquid in the spray tank.

(2) The equivalent model must have the same sloshing frequency and damping force as the liquid in the spray tank.

(3) The center of mass of the liquid in the spray tank remains consistent with the center of mass of the system in the equivalent model.

(4) After the application of lateral excitation, the equivalent model and the liquid in the spray tank generate the same acting force and moment to the tank.

According to the equivalent mechanical model shown in Figure 9, we establish the pendulum model kinetic equation of liquid sloshing as shown in the following:

$$
m_{k} l_{k} \ddot{\theta}+c_{k} l_{k} \dot{\theta}+m_{k} g \theta=m_{k} a .
$$

The acting force of the lateral sloshing of the pendulum model to the spray tank is

$$
F=m_{k} l_{k} \ddot{\theta}-m_{l} a .
$$

The roll sloshing moment of liquid sloshing on the bottom center of the spray tank center is

$$
M=-h_{k}\left(m_{k} l_{k} \ddot{\theta}-m_{l} a\right)+h_{0} m_{0} a+m_{k} l_{k} g \theta .
$$

The physical meanings of parameters in the abovementioned equivalent pendulum model are as shown in Table 4.

The specific calculation formulas for parameters in the equivalent model of liquid sloshing are shown as follows:

$$
\begin{aligned}
m_{l} & =\rho h_{b} \mathrm{lb}, \\
m_{k} & =m_{l} \frac{b}{3.87 h_{b}} \tan h \frac{3.14 h_{b}}{b}, \\
m_{0} & =m_{l}-m_{k}, \\
h_{k} & =\left(1-\frac{m_{k}}{2 m_{l}}\right) h_{b}, \\
h_{0} & =\frac{m_{0}}{2 m_{l}} h_{b} .
\end{aligned}
$$




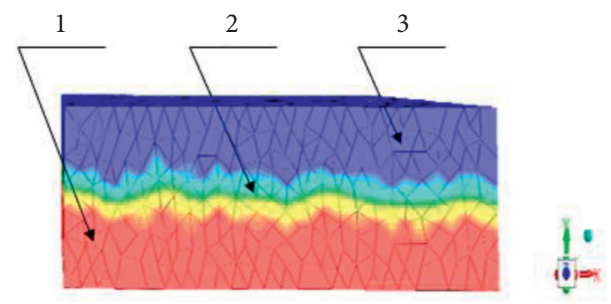

Figure 4: Schematic diagram of the two-phase flow in the spray tank.

Table 3: Fluent simulation setting.

\begin{tabular}{|c|c|c|c|}
\hline Parameter & Option & Parameter & Option \\
\hline Calculation pattern & 3D double precision & Unit condition & $\begin{array}{c}\text { Apply stochastic acceleration on the spray tank in three } \\
\text { directions }\end{array}$ \\
\hline Solver & Pressure solver & Speed and pressure coupling & PISO \\
\hline Solving model & VOF model & $\begin{array}{l}\text { Unit gradient interpolation } \\
\text { method }\end{array}$ & Green-gauss cell-based \\
\hline Viscosity model & $\begin{array}{c}\text { Standard } k-\varepsilon \\
\text { turbulence model }\end{array}$ & $\begin{array}{l}\text { Dispersion scheme of the } \\
\text { pressure modification } \\
\text { coefficient }\end{array}$ & Body force weighted \\
\hline Flow model & Transient flow & Monitoring parameter & $\begin{array}{l}\text { Impact force on the sidewall (the curved surface) of the } \\
\text { spray tank; impact moment on the bottom center of the } \\
\text { spray tank }\end{array}$ \\
\hline $\begin{array}{l}\text { Dispersion scheme of } \\
\text { convection terms }\end{array}$ & $\begin{array}{l}\text { First-order upwind } \\
\text { scheme }\end{array}$ & Initialization & Mixed initialization; path liquid phase \\
\hline Material & $\begin{array}{l}\text { Water (main phase); } \\
\text { air (second phase) }\end{array}$ & Timestep & $0.01 \mathrm{~s}$ \\
\hline
\end{tabular}

The pendulum mode of liquid sloshing built in this paper can be approximately deemed as at the center point of the spray tank; namely, all rotations are deemed as near such point. Therefore, the distance between the center of the spray tank and the center of mass of the pendulum can be approximately deemed as the equivalent pendulum length $1_{k}$.

$$
l_{k}=\frac{g}{w_{i j}^{2}} \text {. }
$$

The data in Table 5 are derived according to formulas (1)-(10) and used in the following calculations [15]:

$$
w_{i j}^{2}=\pi \sqrt{\frac{i^{2}}{b^{2}}+\frac{j^{2}}{l^{2}}} \tanh \left(\pi h_{b} \sqrt{\frac{i^{2}}{b^{2}}+\frac{j^{2}}{l^{2}}}\right) g,
$$

where $i$ and $j$ are, respectively, the number of half-waves in two orthogonal directions within the cross section.

The damping ratio is calculated with the logarithmic decrement method according to [16-18]

$$
\xi=\frac{1}{2 \pi n} \ln \frac{h_{1}}{h_{n+1}},
$$

where $h_{1}$ and $h_{n+1}$, respectively, represent the wave heights of the $1^{\text {st }}$ and the $n+1^{\text {th }}$ vibration cycles.

The damping of liquid sloshing in the rigid spray tank is small, and the influence of the shape of the spray tank on the damping is not sensitive; therefore, the approximate calculation formula of the damping of small damping system is

$$
c_{k}=\frac{2 \pi \xi}{\sqrt{1-\xi^{2}}}
$$

Table 6 shows the parameters of the equivalent pendulum model of liquid sloshing in the wide spray tank calculated from the above formulas.

The above calculations are parameters of the equivalent pendulum model with the spray tank $0.5 \mathrm{~m}$ long $* 0.4 \mathrm{~m}$ wide, and according to the similarity principle of fluid mechanics, the relevant parameters in the above pendulum model have to be magnified accordingly to obtain parameters of the spray tank of $2 \mathrm{~m}$ long $* 1 \mathrm{~m}$ wide in this paper, as shown in Table 7.

\section{Verification of Equivalent Mechanical Model}

We designed an equivalent model in MATLAB/Simulink based on the parameters obtained from the above calculations to calculate the impact force and moment of liquid sloshing and verify the accuracy of the equivalent pendulum model by comparing the calculation results obtained from Fluent numerical simulation and the equivalent model of liquid sloshing in the spray tank. The comparison results are as shown in Figures 10 and 11. The maximum impact force and average to the spray tank solved from the equivalent mechanical model are $19.6 \mathrm{~N}$ and $0.47 \mathrm{~N}$, respectively, and the maximum moment and average moment on the bottom center of the spray tank are $0.6 \mathrm{~N} / \mathrm{m}$ and $0.04 \mathrm{~N} / \mathrm{m}$, respectively. 


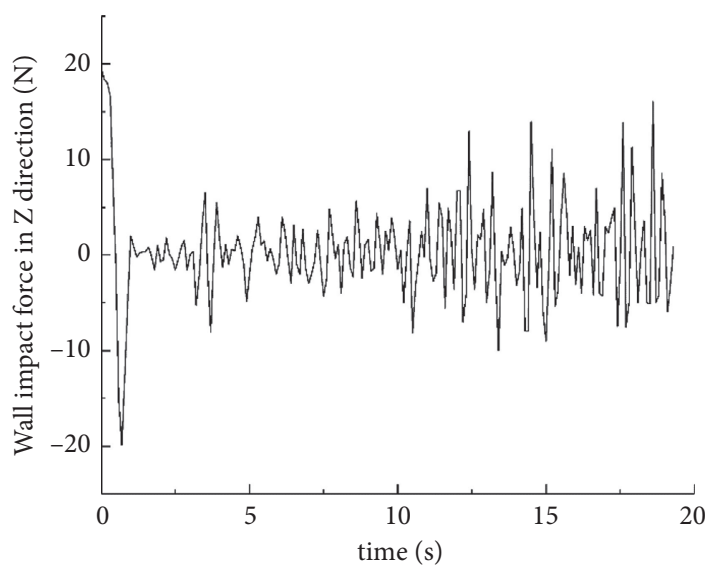

FIGURE 5: Impact force on the spray tank wall surface in $Z$ direction.

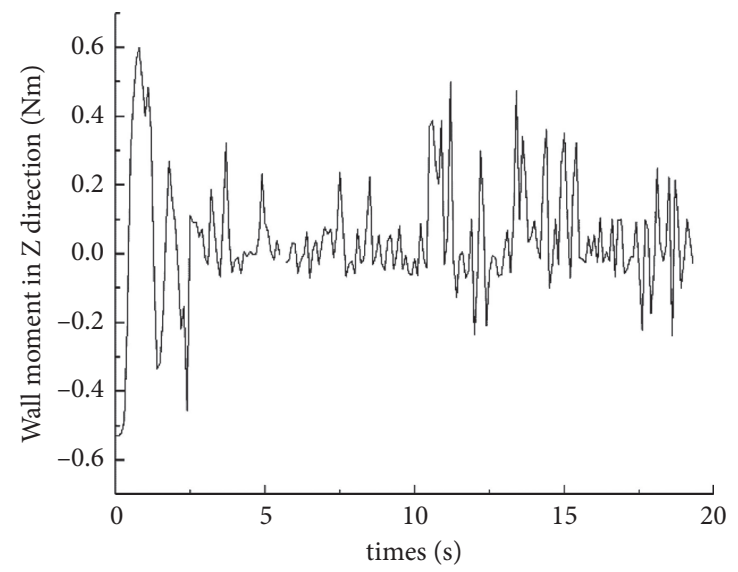

FIgURE 6: Central moment at the spray tank bottom surface in $Z$ direction.

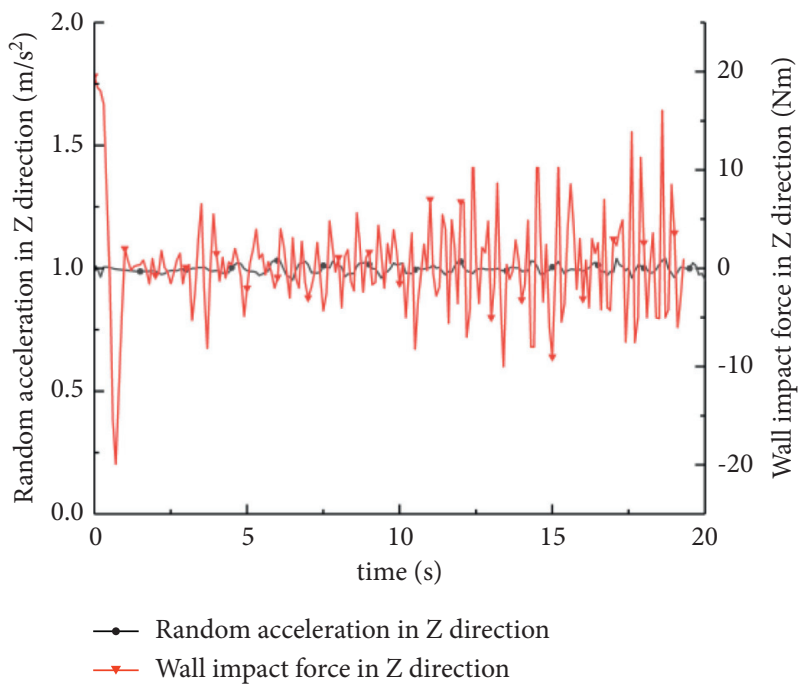

FIGURE 7: Relationship between stochastic acceleration and impact force. 


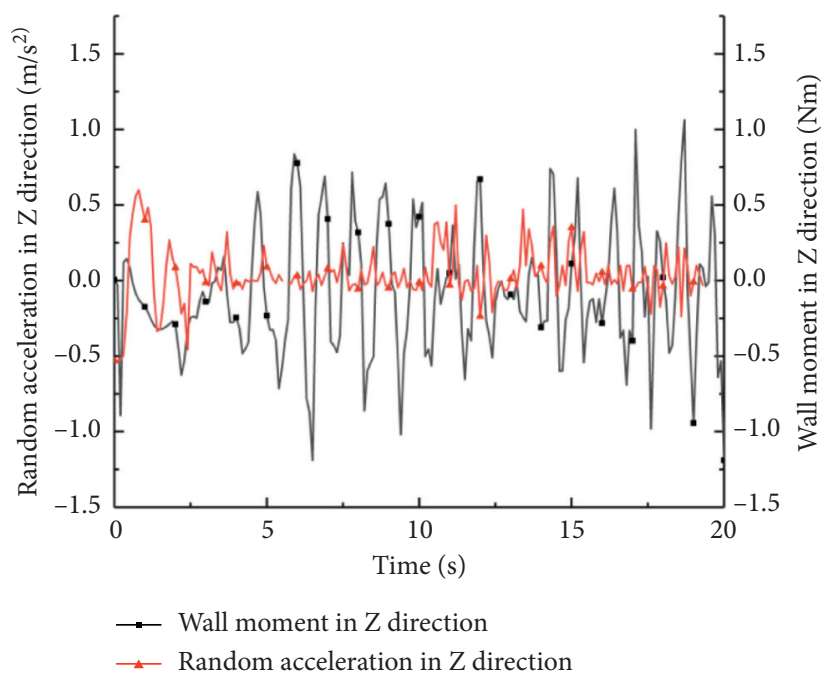

Figure 8: Relationship between stochastic acceleration and impact moment.

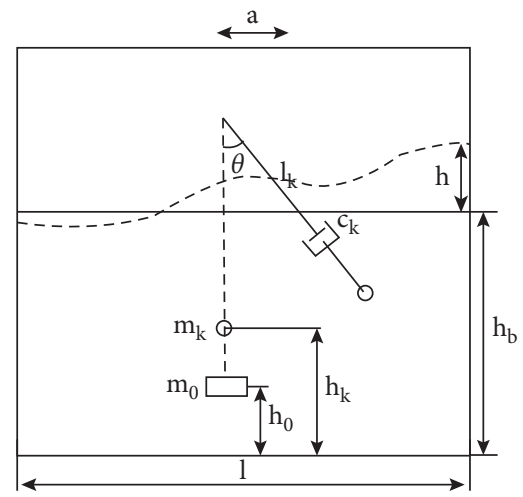

Figure 9: Schematic diagram of the liquid sloshing equipment model.

TABle 4: Physical meanings of parameters in the liquid sloshing pendulum model.

\begin{tabular}{|c|c|c|c|}
\hline Parameter & Physical meaning of parameter & Parameter & Physical meaning of parameter \\
\hline$m_{k}$ & Equivalent pendulum mass of the liquid sloshing & $m_{0}$ & Fixed mass of the liquid sloshing \\
\hline$m_{l}$ & Total mass of the liquid in the spray tank & $\theta$ & $\begin{array}{c}\text { Pendulum angle of the equivalent pendulum of liquid } \\
\text { sloshing }\end{array}$ \\
\hline$c_{k}$ & Damping coefficient of the equivalent model & $l_{k}$ & Length of the equi \\
\hline$h_{k}$ & $\begin{array}{l}\text { Height of the center of mass of the pendulum from the } \\
\text { bottom of the spray tank }\end{array}$ & $h_{0}$ & $\begin{array}{c}\text { Height of the center of mass of fixed mass from the } \\
\text { bottom of the spray tank }\end{array}$ \\
\hline$L$ & Width of the spray tank & $h_{b}$ & Height of the liquid in the spray tank \\
\hline$B$ & Length $\mathrm{c}$ & $h$ & Wave height of the liquid sloshing \\
\hline$h_{l}$ & $\begin{array}{l}\text { Height of the center of mass of liquid to the bottom of the } \\
\text { spray tank }\end{array}$ & $a$ & Lateral acceleration of the spray tank \\
\hline
\end{tabular}

As can be seen from Figures 10 and 11, under the excitation of the stochastic acceleration, the impact force of liquid sloshing oscillates constantly with time and the variation trend is the same as that of the external acceleration.

The amplitude of oscillation of the impact force increases gradually, with the moment first increasing and then decreasing. The simulation results of the equivalent model of liquid sloshing built with MATLAB/Simulink are consistent with the numerical simulation results from using Fluent, where the maximum error in impact force is $2.2 \%$ and the maximum error at the moment is $15 \%$. Thus, the built equivalent model can better describe the sloshing behavior of liquid in the spray tank. Therefore, the 
TABLE 5: Free sloshing frequency of liquid in the rectangular spray tank.

\begin{tabular}{lc}
\hline Frequency order of liquid sloshing & Value $\left.^{-1}\right)$ \\
\hline$w_{00}$ & 0 \\
$w_{10}$ & 1.36 \\
$w_{01}$ & 0.8702 \\
$w_{11}$ & 2.23 \\
$w_{20}$ & 5.439 \\
$w_{02}$ & 3.481 \\
$w_{12}$ & 4.841 \\
$w_{21}$ & 6.309 \\
$w_{22}$ & 8.92 \\
\hline
\end{tabular}

TABle 6: Parameters of equivalent pendulum model.

\begin{tabular}{lc}
\hline Parameter & Value \\
\hline$m_{k}$ & $0.3651 \mathrm{~kg}$ \\
$m_{l}$ & $10 \mathrm{~kg}$ \\
$c_{k}$ & 0.4063 \\
$h_{k}$ & $0.04909 \mathrm{~m}$ \\
$l$ & $0.4 \mathrm{~m}$ \\
$b$ & $0.5 \mathrm{~m}$ \\
$h_{l}$ & $-0.02494 \mathrm{~m}$ \\
$m_{0}$ & $9.635 \mathrm{~kg}$ \\
$l_{k}$ & $1.97068 \mathrm{~m}$ \\
$h_{0}$ & $0.0240875 \mathrm{~m}$ \\
$h_{b}$ & $0.05 \mathrm{~m}$ \\
$h$ & $0.045 \mathrm{~m}$ \\
\hline
\end{tabular}

TABLE 7: Relevant parameters of the pendulum model of the $2 \mathrm{~m}$ long $* 1 \mathrm{~m}$ wide spray tank.

\begin{tabular}{lr}
\hline Parameter & Value \\
\hline$m_{k}$ & $0.54765 \mathrm{~kg}$ \\
$c_{k}$ & 0.60945 \\
$h_{k}$ & $0.073635 \mathrm{~m}$ \\
$l$ & $2 \mathrm{~m}$ \\
$b$ & $1 \mathrm{~m}$ \\
$l_{k}$ & $2.95602 \mathrm{~m}$ \\
\hline
\end{tabular}

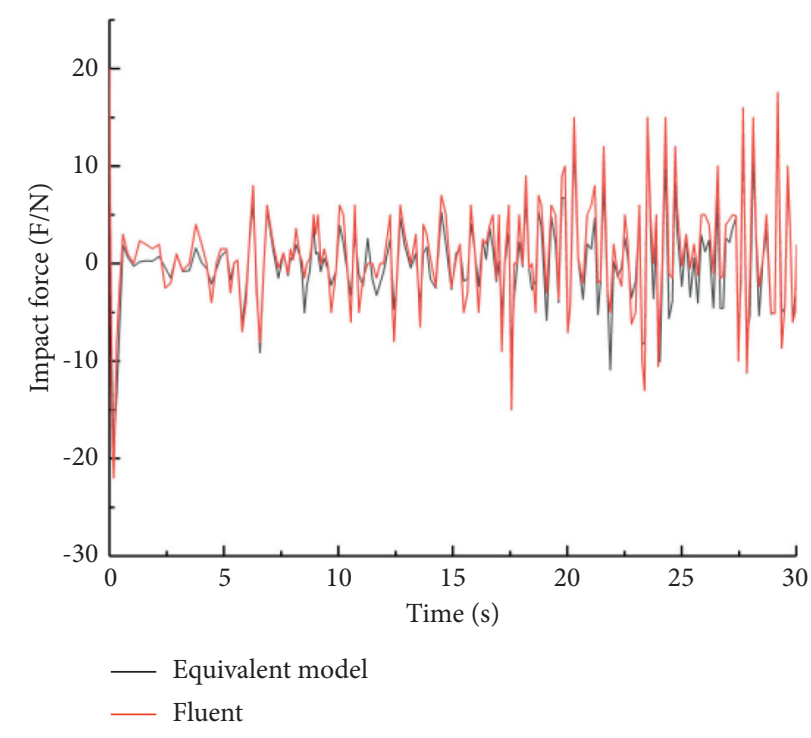

Figure 10: Impact force of liquid sloshing. 
research in this paper will provide references for the modeling of the chassis system kinetic model and the stability control strategies of the high-clearance sprayer.

\section{Building the High-Clearance Sprayer Kinetic Model}

The high-clearance sprayer model was designed based on the equivalent mechanical model of the pendulum mass damping of liquid sloshing built in the above section in combination with the overall high-clearance sprayer rigid model $[19,20]$, as shown in Figure 12. When researching the roll and driving stability of a high-clearance sprayer on a level road, we neglected the pitching and vertical motion and assumed the steering angle of the front wheel to be small; namely, the lateral force of the tire can be expressed by the linear tire slip model.

5.1. Kinetic Model. Lateral movement of the high-clearance sprayer is as follows:

$$
\begin{aligned}
M u\left(\frac{d \beta}{d t}+w\right) & -M_{l} h_{l} \frac{d^{2} \varphi}{\delta t^{2}}-\left(h_{k}+l_{k}+Z_{0}+Z_{1}\right) m_{k} \frac{d^{2} \varphi}{\delta t^{2}} \\
& -m_{k} l_{k}=\sum_{i=1}^{4} F_{y i} .
\end{aligned}
$$

Yawing movement of the high-clearance sprayer is as follows:

$$
I_{z} \frac{d w}{d t}=\left(F_{y 1}+F_{y 2}\right) b_{1}-\left(F_{y 3}+F_{y 4}\right) b_{2} .
$$

Roll movement of the high-clearance sprayer is as follows:

$$
\begin{aligned}
I_{x} \frac{d^{2} \varphi}{\partial t^{2}}-\left[M_{l} h_{l}+\left(h_{k}+l_{k}+Z_{0}+Z_{1}\right) m_{k}\right] u\left(\frac{d \beta}{d t}+w\right) \\
-\left(h_{k}+l_{k}+Z_{0}+Z_{1}\right) l_{k} \frac{d^{2} \cos \theta}{d t^{2}} \\
=-\left(D_{f}+D_{r}\right) \frac{d \varphi}{d t}-\left(C_{\varphi f}+C_{\varphi r}\right) \varphi+M_{l} h_{l} g \varphi .
\end{aligned}
$$

5.2. Tire Model. Assume the steering angle of the front wheel of the high-clearance sprayer $(\delta, \mathrm{rad})$ and use the linear tire slip model; the slip angles of tires from the first axle to the fourth axle can be separately described as [21]

$$
\left\{\begin{array}{l}
a_{1}=\beta_{1}+\frac{\omega_{1}}{u} a_{1}-\delta \\
a_{2}=\beta_{1}-\frac{\omega_{1}}{u} b_{1}, a_{3}=\beta_{1}-\frac{\omega_{1}}{u} b_{2}, \\
a_{i}=\beta_{1}-\frac{\left(l_{p}+a_{2}+b_{i-1}\right) \omega_{1}}{u}-\frac{\left(a_{2}-b_{i-1}\right)(d \theta / d t)}{u}-\theta, \quad(i=4,5,6) .
\end{array}\right.
$$
as

The lateral force of each tire can be separately expressed

$$
F_{y 1}=F_{y 2}=C_{y f} a_{1}, F_{y 3}=F_{y 4}=C_{y r} a_{2} .
$$

Meanings and values of parameters in the model system are shown in Table 8 .

\subsection{Simulation Test and Analysis}

5.3.1. Influence of the Driving Speed on the Stability of the Sprayer. Considering that it is dangerous to test drive at high speed, this paper selects the simulation test method for analysis. The filling ratio $k$ is defined as the ratio between the liquid depth $h_{b}$ and the spray tank height $h$, namely, $k=h_{b} / \mathrm{H}$. To research and analyze the influence of the driving speed on the stability of a high-clearance sprayer with a certain filling ratio, we set the filling ratio $k$ as 0.5 and the driving speed $u$ as $1 \mathrm{~m} / \mathrm{s}$, $2 \mathrm{~m} / \mathrm{s}$, and $3 \mathrm{~m} / \mathrm{s}$, respectively, during the simulation test. The simulation analysis results are as shown in Figure 13, and the input external stochastic acceleration is as shown in Figure 14.

As can be seen from Figure 13, in the case of the filling ratio $k=0.5$, stochastic acceleration, and different speed conditions, the liquid sloshing has a small influence on the roll angle of the high-clearance sprayer but has a big influence on the slip angle of the center of mass and the yaw angular velocity. This is attributable to the liquid flowing outwards under the action of centrifugal force and increasing the lateral displacement of the center of mass of the liquid. On the other hand, the dynamic pressure produced by liquid sloshing due to the increased speed also increases the slip angle of the center of mass and the yaw angular velocity. When the driving speed is increased to $3 \mathrm{~m} / \mathrm{s}$ from $1 \mathrm{~m} / \mathrm{s}$, the slip angle of the center of mass increases by $46 \%$ 


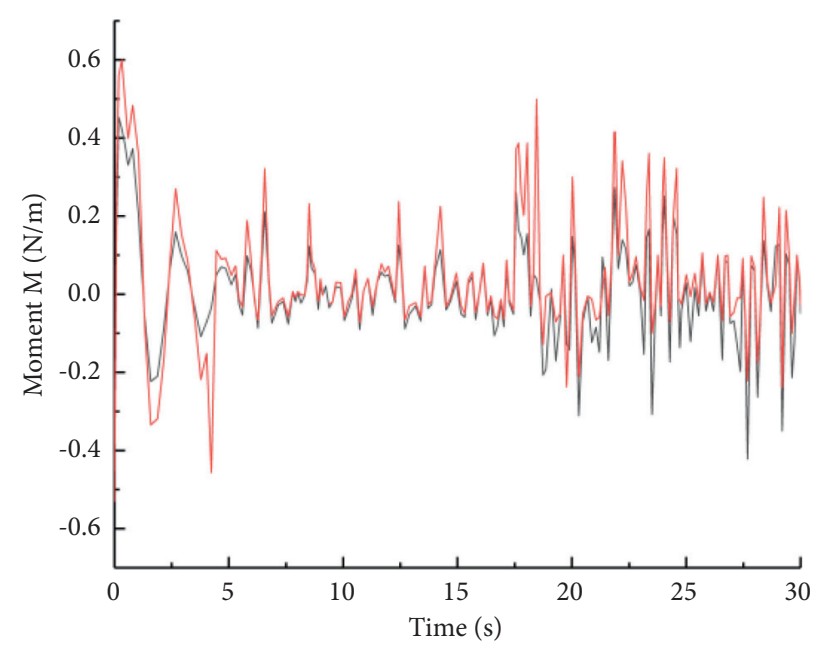

Equivalent model

FIGURE 11: Liquid sloshing moment.

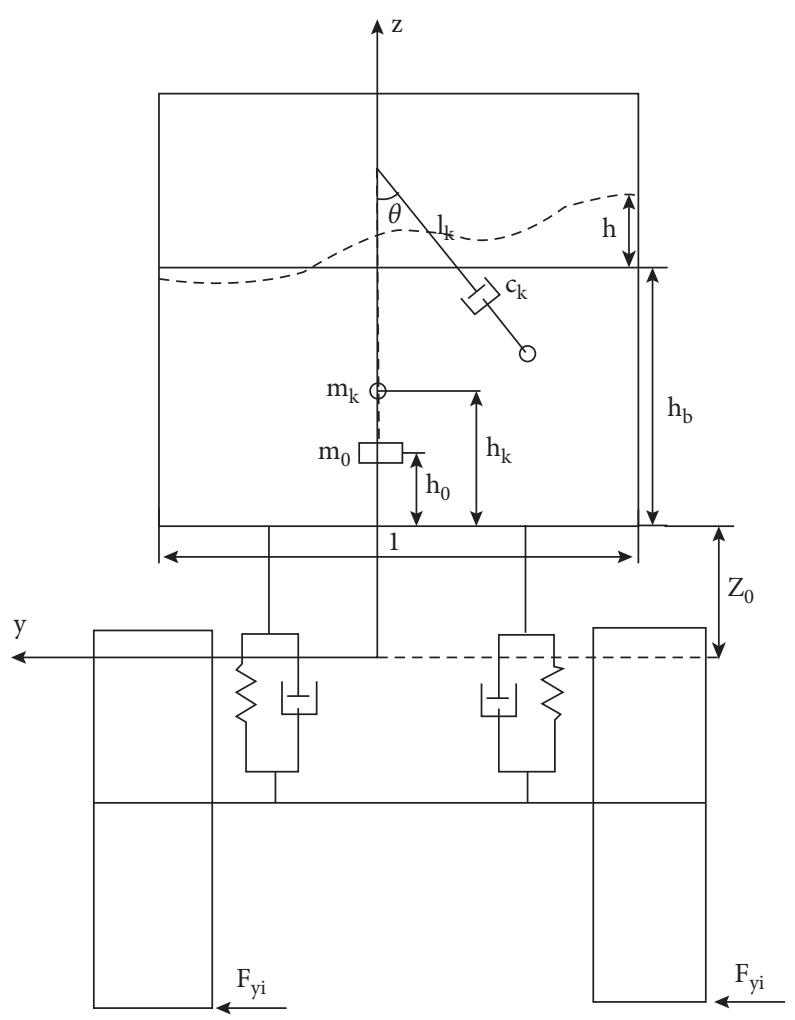

FIGURE 12: Roll model of the high-clearance sprayer.

and $40 \%$, respectively, the yaw angular velocity increases by $20 \%$ and $13 \%$, respectively, and the roll angle of the sprung mass increases by $8.5 \%$ and $2.6 \%$, respectively. As can be seen from the above data, when the driving speed of the high-clearance sprayer is increased to $3 \mathrm{~m} / \mathrm{s}$ from $2 \mathrm{~m} / \mathrm{s}$, the liquid sloshing is violent; as a result, we can conclude that it is safe to maintain the driving speed of the high-clearance sprayer between $1 \mathrm{~m} / \mathrm{s}$ and $2 \mathrm{~m} / \mathrm{s}$ when working in the field.
5.3.2. Influence of the Filling Ratio on the Stability of Sprayer. To research and analyze the influence of different filling ratios on the stability of high-clearance sprayers, we set $u=2 \mathrm{~m} / \mathrm{s}$ and set a as the stochastic acceleration in the simulation test. Figure 15 shows the simulation results.

As can be seen from Figure 15, when $u=2 \mathrm{~m} / \mathrm{s}$ and at stochastic acceleration, the filling ratio greatly influences the roll angle, the slip angle of the center of mass, and the yaw 
TABLE 8: System parameters.

\begin{tabular}{|c|c|c|}
\hline Parameter & Meaning & Value \\
\hline$M$ & Total mass of the high-clearance sprayer, including the liquid $(\mathrm{kg})$ & 1546 \\
\hline$M_{l}$ & Sprung mass of the high-clearance sprayer with no load $(\mathrm{kg})$ & 976 \\
\hline$h_{l}{ }^{l}$ & Distance from the center of the sprung mass of the high-clearance sprayer with no load to the roll axis $(\mathrm{m})$ & 1 \\
\hline$\varphi$ & Roll angle of the sprung mass of the high-clearance sprayer (rad) & \\
\hline$I_{z}$ & Yaw rotational inertia of the high-clearance sprayer including liquid $\left(\mathrm{kg} \bullet \mathrm{m}^{2}\right)$ & \\
\hline$I_{X}$ & Roll rotational inertia of the high-clearance sprayer including liquid $\left(\mathrm{kg} \bullet \mathrm{m}^{2}\right)$ & \\
\hline$w$ & Yaw angular velocity of the high-clearance sprayer $\left(\mathrm{rad}_{\bullet} \mathrm{s}^{-1}\right)$ & \\
\hline$\beta$ & Slip angle of the center of mass of the high-clearance sprayer (rad) & \\
\hline$b_{1}$ & Distance from the center of mass of the high-clearance sprayer to the front axle (m) & 1.6 \\
\hline$b_{2}$ & Distance from the center of mass of the high-clearance sprayer to the rear axle (m) & 1.4 \\
\hline$D_{f}$ & Roll damping of the front suspension of the high-clearance sprayer $\left(\mathrm{N} \bullet \mathrm{s} \bullet \mathrm{m} \bullet \mathrm{rad}^{-1}\right)$ & 400 \\
\hline$D_{r}$ & Roll damping of the rear suspension of the high-clearance sprayer $\left(\mathrm{N} \bullet \mathrm{s} \bullet \mathrm{m} \bullet \mathrm{rad}^{-1}\right)$ & 400 \\
\hline$C_{\varphi f}$ & Roll angle stiffness of the front suspension of the high-clearance sprayer $\left(\mathrm{N} \bullet \mathrm{s} \bullet \mathrm{m} \bullet \mathrm{rad}^{-1}\right)$ & 4000 \\
\hline$C_{\varphi r}$ & Roll angle stiffness of the rear suspension of the high-clearance sprayer $\left(\mathrm{N} \bullet \mathrm{s} \bullet \mathrm{m} \bullet \mathrm{rad}^{-1}\right)$ & 4000 \\
\hline$C_{y f}^{\varphi r}$ & Lateral stiffness of the front tire of the high-clearance sprayer $\left(\mathrm{KN} \bullet \mathrm{rad}^{-1}\right)$ & 15 \\
\hline$C_{y r}^{y J}$ & Lateral stiffness of the rear tire of the high-clearance sprayer $\left(\mathrm{KN} \bullet \mathrm{rad}^{-1}\right)$ & 25 \\
\hline$F_{y i}$ & Lateral force of the tires of the high-clearance sprayer $(\mathrm{N})$ & \\
\hline$u^{y t}$ & Driving the speed of the high-clearance sprayer $(\mathrm{m} \bullet \mathrm{s})$ & \\
\hline$Z_{0}$ & Distance between the roll axes at the bottom of the spray tank (m) & 0.8 \\
\hline
\end{tabular}

Note. The parameters $M, I_{z}$, and $I_{X}$ are related to the filling ratio $k$, and the definitions of other parameters are consistent with that of the equivalent mechanical model system of the pendulum mass damping.

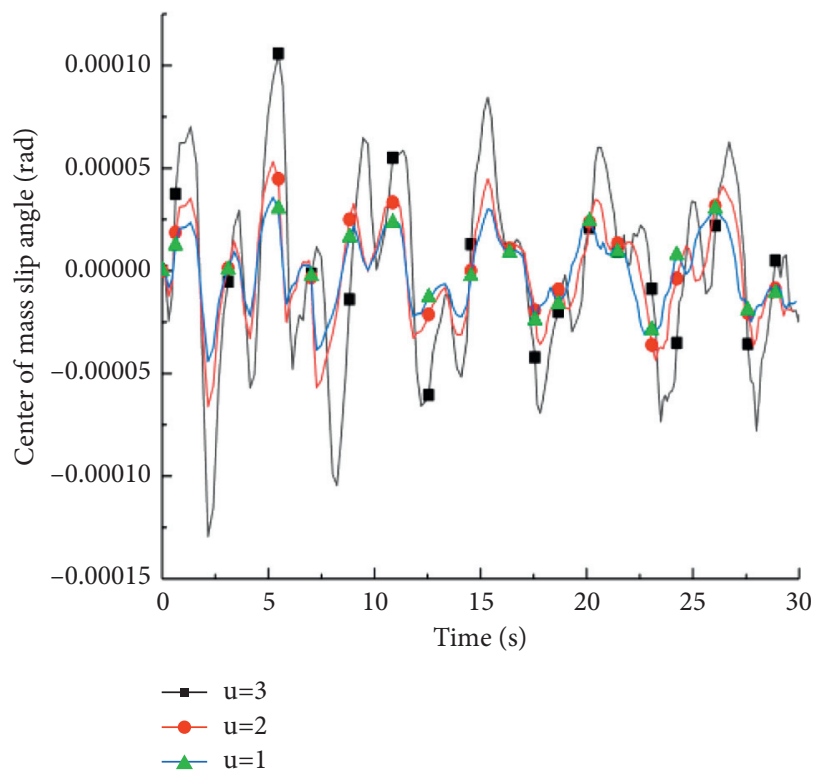

(a)

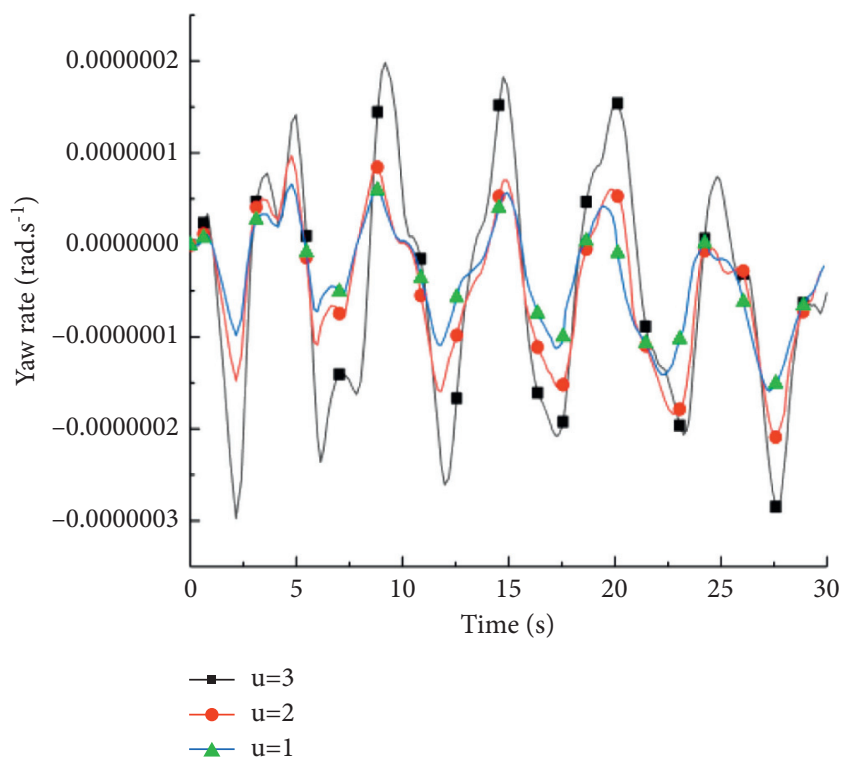

(b)

FIGURE 13: Continued. 


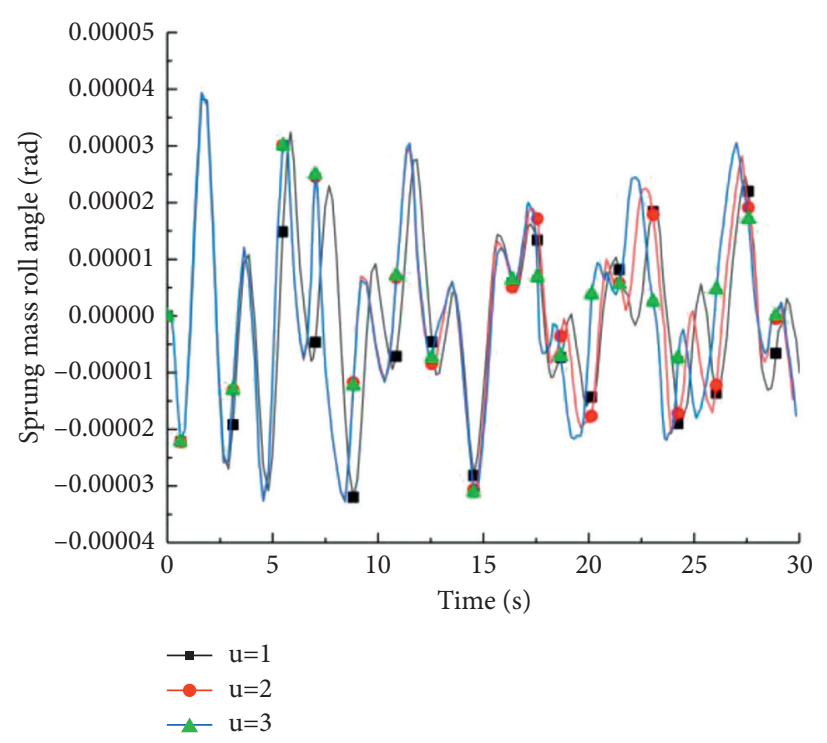

(c)

FIGURE 13: Simulation results of different speeds. (a) Slip angle of the center of mass of the high-clearance sprayer; (b) yaw angular velocity of the sprayer; (c) roll angle of sprung mass of the sprayer.

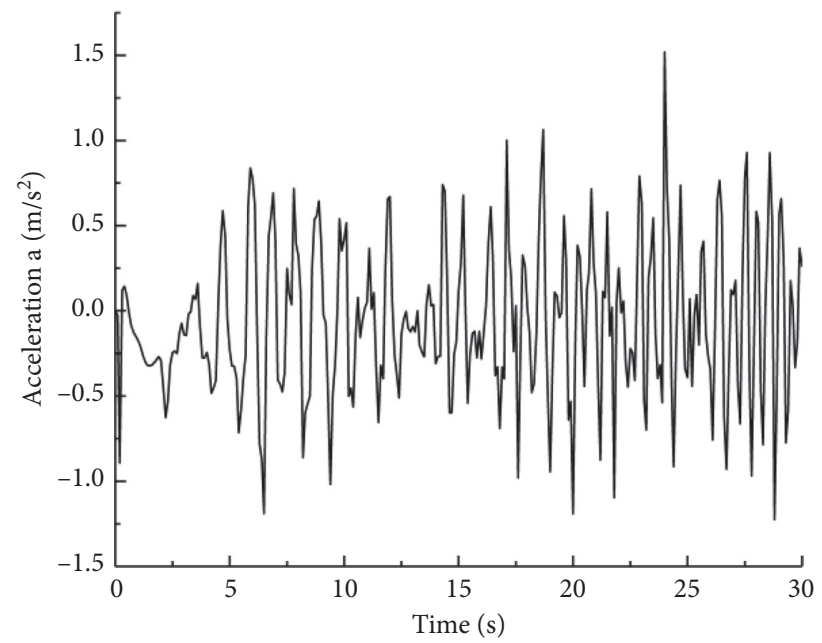

FIGURE 14: Variation curve of stochastic acceleration.

angular velocity of the high-clearance sprayer. This is because, with the increase of the filling ratio, the liquid sloshing produces additional moment and acting force in the spray tank, increasing the roll angle, slip angle of the center of mass, and yaw angular velocity of the high-clearance sprayer. When the filling ratio increases to 0.95 from 0.75 , the roll angle separately increases by $32 \%$ and $75 \%$, the slip angle of the center of mass separately increases by $54 \%$ and $67 \%$, and the yaw angular velocity separately increases by $43 \%$ and $69 \%$. As can be seen from the above data, when the filling ratio of the high-clearance sprayer increases to 0.95 from 0.85 , the liquid sloshing is violent. Consequently, we can conclude that it is safe to maintain the filling ratio of liquid in the spray tank at about 0.85 when the high-clearance sprayer is working.

As can be seen from Figure 16, when the driving speed is $2 \mathrm{~m} / \mathrm{s}$ and a is the stochastic acceleration, the liquid sloshing hugely influences the lateral acceleration of the high-clearance sprayer, and with the increase of the filling ratio, the lateral acceleration will increase randomly. When the filling ratio increases to 0.95 from 0.75 , the lateral acceleration will increase by 12.4 and 26.4 , respectively. $u$, as depicted in the above data, improves the operating efficiency and the driving stability of the highclearance sprayer while working, and the best filling ratio is 0.85 . 


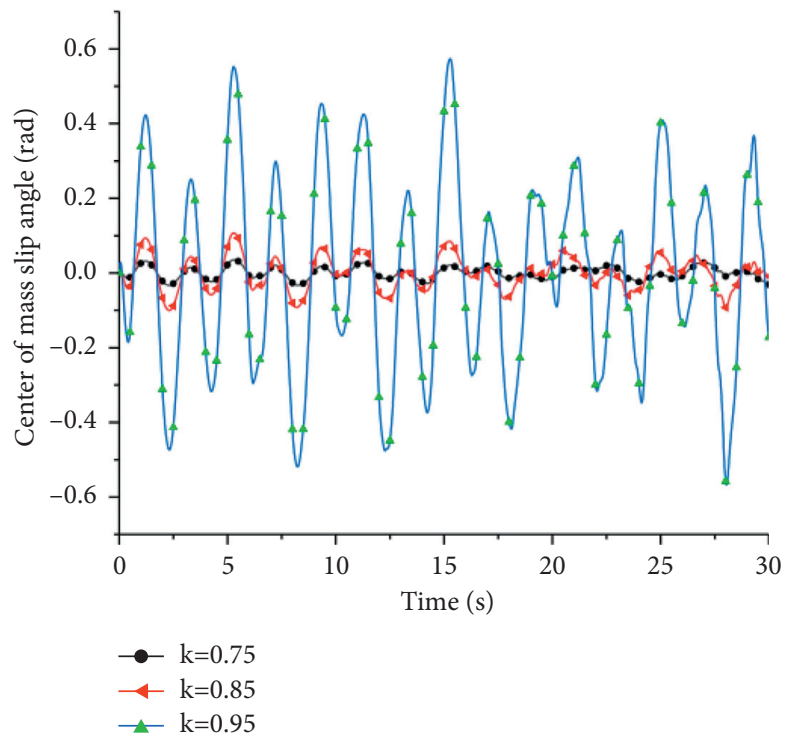

(a)

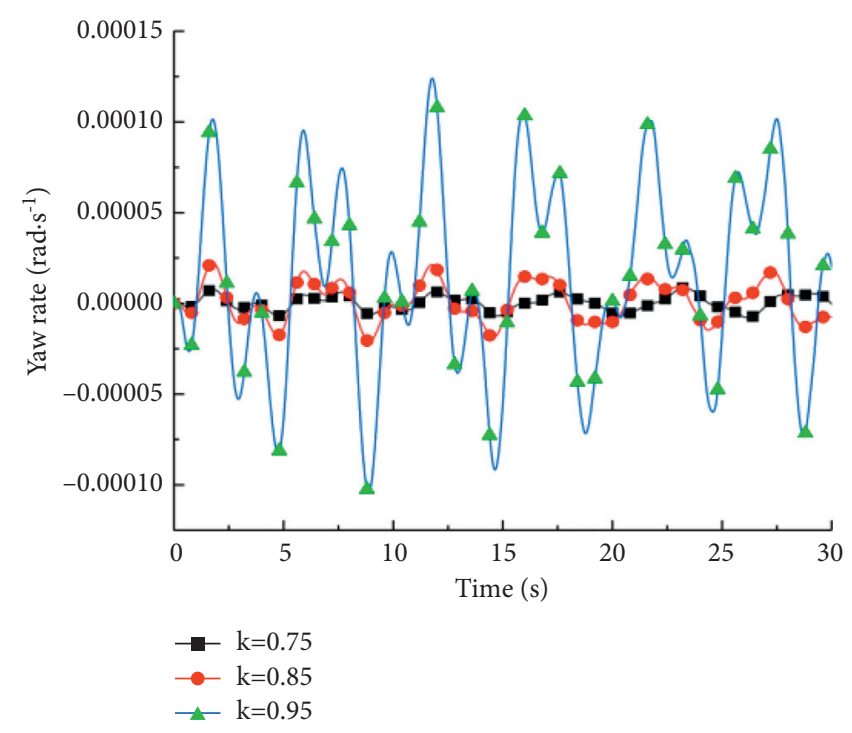

(b)

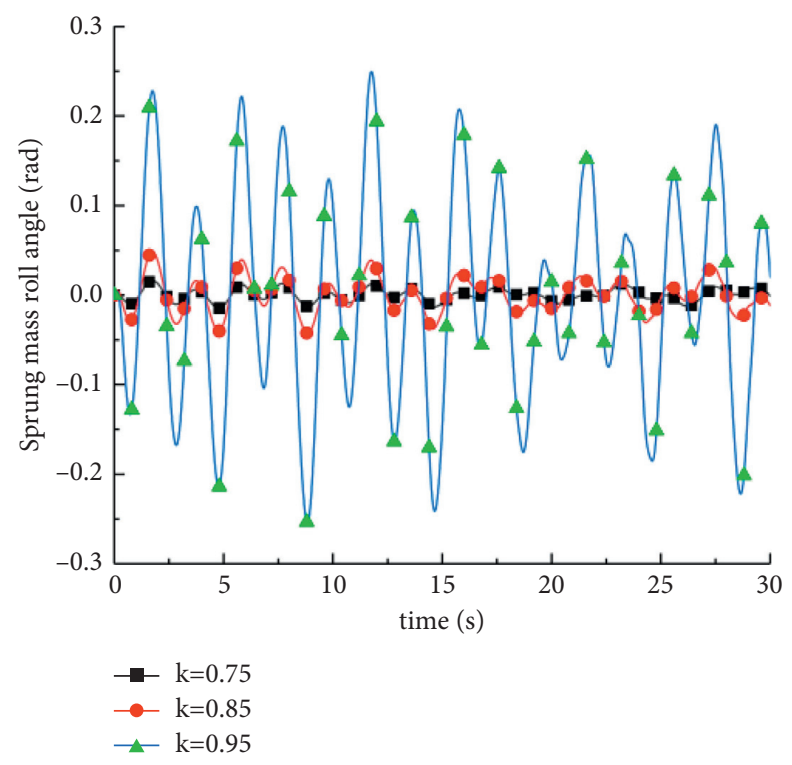

(c)

FIGURE 15: Simulation results of different filling ratio. (a) Variation curve of the slip angle of the center of mass. (b) Variation curve of yaw angular velocity. (c) Variation curve of mass roll angle. 


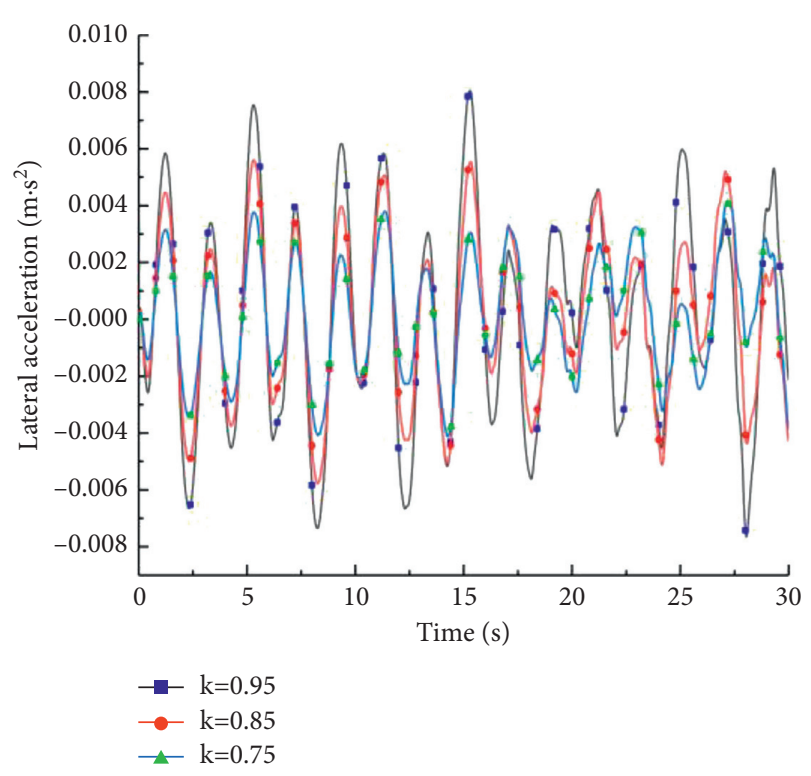

FIgURE 16: Lateral acceleration curves of the high-clearance sprayer.

\section{Conclusions}

(1) By researching the liquid sloshing in the spray tank, we were able to design a kinetic model of the highclearance sprayer and simulate two working conditions, namely, a particular filling ratio and different driving speeds. Also, certain driving speeds, different filling ratios, and simulation results show that liquid sloshing has a different influence on the driving parameters of a high-clearance sprayer under these two working conditions. Under the working condition of certain filling ratio and different driving speeds, liquid sloshing has a small influence on the roll angle of the high-clearance sprayer, while under the working condition of certain driving speeds and different filling ratios, liquid sloshing has a big influence on the driving parameters of the highclearance sprayer.

(2) When the driving speed is increased to $3 \mathrm{~m} / \mathrm{s}$ from $1 \mathrm{~m} / \mathrm{s}$, the liquid flows outwards under the action of centrifugal force and increases the lateral displacement of the center of mass of liquid. Meanwhile, the dynamic pressure produced by liquid sloshing due to the increased speed also increases the slip angle of the center of mass and the yaw angular velocity. When the driving speed is increased to $3 \mathrm{~m} / \mathrm{s}$ from $2 \mathrm{~m} / \mathrm{s}$, the liquid sloshing becomes violent, so we can conclude from the analysis that it is appropriate to maintain the driving speed between $1 \mathrm{~m} / \mathrm{s}$ and $2 \mathrm{~m} / \mathrm{s}$ when the sprayer is working.

(3) When the filling ratio increases to 0.95 from 0.75 , the liquid mass in the spray tank increases, and the sloshing force and inertia force produced by liquid jointly act on the sprayer to aggravate the yawing motion and lateral acceleration. When the filling ratio increases to 0.95 from 0.85 , the liquid mass participating in sloshing gradually increases, and the produced sloshing force has a big influence on the yawing motion and lateral acceleration of the sprayer. Therefore, considering the working efficiency of a high-clearance sprayer in the field, when the filling ratio $\mathrm{K}$ is about 0.85 , the liquid sloshing in the spray tank has a small influence on the driving stability of high-clearance sprayer, so such filling ratio is a preferential filling ratio for high-clearance sprayers in operation.

\section{Data Availability}

Previously reported data are used to support this study and are cited at relevant places within the text as references.

\section{Conflicts of Interest}

The authors declare that they have no conflicts of interest.

\section{Acknowledgments}

This study was supported by the High-Level Talents Research Start-Up Fund of Shihezi University, RCZK2018C07.

\section{Supplementary Materials}

Additional files (force, moment $M$, and stochastic acceleration), which are the comparative data, are used in the equivalent mechanical model results. Among them, the stochastic acceleration is used in the paper. In the Fluent software simulation, the stochastic acceleration is dynamically loaded into the UDF, and stochastic acceleration is also used in the equivalent mechanical model. (Supplementary Materials)

\section{References}

[1] Y. Han and H. Zhang, "Comprehensive control technology of maize spider mites in Yili area," Xinjiang Agricultural Science and Technology, vol. 2, p. 34, 2007.

[2] Z. L. H. Zheng, "Modelling and analysis of the influences of various liquid sloshing characteristics on tank truck dynamics," International Journal of Heavy Vehicle Systems, vol. 26, no. 3-4, p. 463, 2019.

[3] V. E. Klubnichkin and E. E. Klubnichkin, "Effect of structural parameters on roll motions of the wheeled timber harvesting vehicle," IOP Conference Series: Materials Science and Engineering, vol. 971, no. 5, p. 5, 2020.

[4] M. H. Z. Rui, Research on Autonomous Driving Control Method of Intelligent Vehicle Based on Vision Navigation, IEEE, Piscataway, NJ, USA, 2010.

[5] C. Y. Tang and Y. F. Zhao, "Research on intelligent vehicle trajectory tracking control method," Journal of Northeastern University, vol. 41, no. 9, pp. 1297-1303, 2020.

[6] X. J. Sa and M. Y. Wu, "Research on the tipping stability of high ground clearance sprayer for flood and drought," Journal of Gansu Agricultural University, vol. 53, no. 6, pp. 221-230, 2018. 
[7] V. Armenio and M. La Rocca, "On the analysis of sloshing of water in rectangular containers: numerical study and experimental validation," Ocean Engineering, vol. 23, no. 8, pp. 705-739, 1996.

[8] B. Z. Yue and L. M. Zhu, "Recent advances in liquid-filled tank dynamics and control," Advances in Mechanics, vol. 41, no. 1, pp. 79-92, 2011.

[9] G. P. KLi and L. Qing, "Liquid sloshing model and sloshing torque analysis of large satellite with tiled tan," Aerospace Shanghai, vol. 28, no. 1, pp. 18-22, 2011.

[10] X. S. Cheng and Y. FDu, "The dynamic fluid pressure of reinforced concrete rectangular liquid-storage tanks with elastic walls," Engineering Mechanics, vol. 26, no. 6, pp. 82-88, 2009.

[11] S. Aliabadi, A. Johnson, and J. Abedi, "Comparison of finite element and pendulum models for simulation of sloshing," Computers \& Fluids, vol. 32, no. 4, pp. 535-545, 2003.

[12] S. J. Pan and K. Ma, "Stability-based integrated control method for intelligent vehicles," Journal of Military Transportation Academy, vol. 22, no. 7, pp. 38-45, 2020.

[13] C. Y. Liu and L. Q. Liu, "Study on sloshing fluid in fully open moonpool based on equivalent pendulum model," Journal of Tianjin University Of Technology, vol. 1, pp. 45-5, 2015.

[14] X. M. Hu and W. L. Li, "Liquid sloshing reduces driving stability of semi-trailer liquid tank," Transactions of the Chinese Society of Agricultural Engineering, vol. 29, no. 6, pp. 49-58, 2013.

[15] G. W. Bao and Z. W. Wang, "A finite element numerical calculation method for liquid three-dimensional wobble characteristic problem," Quarterly Journal of Mechanics, vol. 2, pp. 185-190, 2003.

[16] C. N. Song and G. L. Zhou, "Experiment on sloshing dynamics of irregular annular cylinder water tank," Journal of Harbin Engineering University, vol. 39, no. 1, pp. 187-192, 2018.

[17] D. Z. Ning and W. H. Song, "Effect of natural frequencies of container on fluid sloshing," Advances in Marine ence, vol. 30, no. 1, pp. 45-53, 2012.

[18] B. Z. Yue and L. M Zhu, "Recent advances in liquid-filled tank dynamics and control," Advances in Mechanics, vol. 41, no. 1, pp. 79-92, 2011.

[19] C. F. Z. L. Mai, "Dynamic modeling and roll stability analysis of heavy tractor semi-trailers," Journal of Liaoning University of Technology, vol. 28, no. 1, pp. 52-56, 2008.

[20] Z. X. Yu and C. F. Zong, "Stability controlstrategy for heavy semi-trailer train based on linear quadratic regulator," China Journal of Highway and Transport, vol. 24, no. 2, pp. 114-119, 2011.

[21] T. J. Zhu, Research on Improved TTR Rollover Warning and Multi- Objective Stability Control Algorithm of HeavyDuty Vehicle, Jilin University, Changchun, China, 2010. 